\title{
Renewing the Governance of Rural Land after Brexit: an Ecosystems Policy Approach
}

\author{
lan Hodge
}

Over the past 40 years we have witnessed a major shift in our concerns for the use of rural land. The postwar priority for domestic food production has been replaced by a new perspective that recognises a wider range of values, particularly for landscapes, biodiversity, water and climate. The multifunctionality model sets agricultural commodity production alongside non-commodity public goods (OECD, 2001). This views agriculture as the provider of environmental benefits in joint production with agricultural products. But it sits uncomfortably alongside the mounting evidence of the environmental damage caused by agricultural activities, some of which undermines the productive capacity of the farming industry itself. The recent assessment by the Intergovernmental Science-Policy Platform on Biodiversity and Ecosystem Services (IPBES) confirms that current agricultural practices, encouraged by agricultural policies, are not sustainable. We are experiencing land degradation, loss of biodiversity and ecosystem functions and loss of local plant varieties and breeds of livestock (IPBES, 2019).

Government has at least partially recognised the problems. Policies have been reformed to restrain the most perverse incentives, particularly through decoupling. But many of the policy approaches that give priority to agriculture remain in place. Under the CAP the overwhelming majority of funding directed to influence rural land uses and practices goes to 'active' farmers. However, it is hard to identify any rationale that justifies the direct payments made to landholders. The European Commission (2017 p.3) argues that payments have 'helped European farmers focus more effectively on the demands of the market and strengthened their long term viability'. But it is not clear why payments unrelated to production activity should help a focus on the market, rather the contrary might be expected. And it may be questioned as to why all farms in all circumstances need to have their long term viability strengthened through a fixed rate payment. The payments make 'a very important contribution to overall farm income' but the equal payment across all land areas provide large payments to large businesses and are not targeted on households with low incomes. Further the Commission argues that payments enhance farmers' role in protecting the environment and in the developing the rural economy. In fact as already noted, agricultural production is widely seen as a major cause of environmental harm and the general trend in environmental indicators has been one of decline (RSPB, 2016), most recently highlighted by the evidence of significant decline in insect populations (Powney, et al., 2019). Even the cross-compliance and greening that are directed the environment are standard requirements applied largely indiscriminately across farmed areas with little positive impact (Pe'er et a., 2014) and no attempt to target effort on the areas or actions that could generate the highest marginal environmental benefits. Policies have been introduced, particularly for biodiversity. Conservation measures aim to offer protection for habitats and species that have come under greatest pressure. Agri-environment programmes have been adopted across the European Union and elsewhere with some success, but, the impacts are mixed (Batáry, et al., 2015). In this context, it has been stressed that biodiversity conservation efforts need to be 'more, bigger, better and joined' (Lawton et al., 2010) 
But at the same time, other values deriving from rural land policy have gained greater prominence. Climate change in particular is a major driver of numerous challenges. It exacerbates the present problems; biodiversity has to cope with forces that introduce alien species and change the context within which conservation takes place. Agricultural systems need to reduce their greenhouse gas emissions and take account of the place of carbon in the landscape. It is argued that agriculture needs to change from a net source to a net sink of greenhouse gases (Rockstrom, 2017). Farming needs to adapt to mitigate flood risk and to even out water availability over time. Water quality has not reached the standards required under the EU Water Framework Directive, substantially due to diffuse pollution from farming, and there are renewed concerns about the long term sustainability of soils.

One consequence of Brexit is that the UK, with its devolved administrations in Belfast, Cardiff and Edinburgh, has the opportunity and freedom to develop new responses to the challenges; whilst recognising that these concerns have a wider resonance throughout Europe and elsewhere. The UK Conservative Government aims to be the first to leave the environment in a better state than that in which it found it. The Agriculture Bill paves the way for a simpler system of regulation and enforcement. This prioritises spending on public goods and environmental outcomes (Curnow, 2018). The government's 25 Year Environment Plan sets ambitious goals: clean and plentiful water, thriving plants and wildlife, using resources from nature more sustainably and efficiently, enhanced beauty, heritage and engagement with the natural environment (HM Government, 2018). Clearly ambition is a necessary first step, but there is a gap in terms of the governance arrangements that can deliver the ambition in the 'best' way: Where are land uses to be changed? How are stakeholder values to be taken into account? How is the delivery of different ecosystem services to be integrated within local contexts? How are natural capital generally and the environmental enhancements more particularly to be maintained over time? How does the approach to policy respond to changing priorities, constraints and opportunities over time?

We need to rethink the approach towards the governance of rural land (Hodge, 2016; Dwyer and Hodge, 2016; Martin, 2016; OECD, 2017), to establish institutions that can deliver outcomes after Brexit that meet the contemporary challenges for the maintenance of natural capital and the sustainability of ecosystem services.

\section{The elements of governance}

A first element in the development of any policy is the establishment of an objective. The post war imperative for increased domestic food production stood at the core of agricultural policy but since the surpluses of the 1980s it has increasingly conflicted with other goals, compromising water quality, biodiversity and climate change. We should set a new overarching objective. This should be to maximise the long term social value of the ecosystem services that are derived from natural capital. It will not be possible to quantify this goal, but it represents a clear objective.

This requires further elements of governance. It first demands a clear position with regard to the rights and duties for the ownership and management of land and environment. This sets the reference level or baseline against which decisions can be taken. Our social judgements about where this lies shift over time as scarcities, preferences and constraints alter the nature of the 
domain within which natural resource management takes place. Over time, for example, we have generally come to treat the leaching of nitrates in water from agricultural land as a form of pollution, regulated through nitrate vulnerable zones. We may now question whether the emission of greenhouse gases should be treated similarly, or whether there should be a duty on landholders to maintain levels of carbon in soil.

In a capitalist system most values are determined through the operation of markets as facilitated and constrained by the state. But increasingly large and now, arguably, the predominant values arising from rural land have the characteristics of public goods (and bads). Once provided, it is not possible to exclude people from the impacts, good or bad. Experience of the impact by one person does not deplete the experience impacted on others. Thus, for example, landscapes and biodiversity are generally available to all. Flood protection benefits large numbers of residents and businesses downstream. Carbon sequestration mitigates the impacts of climate change for the global population. In this context we require governance structures for identifying the values on which collective actions can be based.

Some values may be determined though the development of augmented markets or through new domains of exchange. Product certification gives prospective consumers better information about a product and its production methods. Consumers concerned about animal welfare can choose to buy products whose production has been certified to reach certain defined welfare standards. We are beginning to explore the opportunities for the development of new markets for the delivery of ecosystem services (see e.g. Green Alliance, 2017), such as water companies paying land managers for changes in practices that enhance water quality. But the public good nature of many of the ecosystem services places limits on the scope of such markets. Individuals or companies may choose to offset their carbon emissions by paying for afforestation, but such payments are voluntary and, given the incentive to free-ride, the take-up is unlikely to be sufficient to achieve the socially desired level.

\section{Devolved decision-making and implementation}

In the absence of markets, values are formed collectively through various factors such as cultural norms or the operation of the state. The principle of subsidiarity (Alm and Banzhaf, 2012) proposes that decisions should be devolved to the feasible level closest to those affected by the consequences of the decision. In principle that might imply an infinite number of valuation contexts between decisions that affect only me and decisions that affect the whole world. In practice valuation needs to be associated with opportunities to take action in relation to those valuations and here we simply suggest that values can be formed either nationally or locally.

A range of ecosystem values are of evident national or international significance. National governments enter into international commitments, such as the Aichi Targets under the Convention on Biological Diversity or Nationally Determined Contributions towards climate change mitigation. Similarly national governments identify nationally important assets, such as national parks or they set national targets, perhaps for afforestation. Other values are of more local significance. The interactions amongst those affected by water use and water quality will be strongest amongst those living and operating within a particular catchment. The quality of a landscape, biodiversity and 
public access in areas that are not major tourist destinations may be of most importance to those living within the local area.

This logically leads to system of multilevel governance (Ostrom, 2010). The transactions costs of organising structures that bring stakeholders together for the purpose of collective decision-making clearly need to be balanced against the increased validity that may be achieved by more locally based decision-making. In the UK, agriculture is a devolved matter with responsibilities transferred to governments in Scotland, Wales and Northern Ireland. This arrangement has applied to date under the CAP with the oversight of the $\mathrm{EU}$ and Brexit raises complex and controversial questions about the new arrangements to be implemented (House of Lords, 2017). However, in this context, we propose a national (viz. UK and England, Scotland, Wales and Northern Ireland) and a local level of decision-making. The argument here is that some element of decision making should be devolved to a sub-national level.

National agencies would operate funds for the procurement of ecosystem services of national importance, such as for climate mitigation or biodiversity conservation. The approaches taken would be different towards different ecosystem services. A national target for reduction of greenhouse gas emissions would seek to identify the most cost-effective measures, irrespective of location. The national scale would then maximise the cost effectiveness of measures across the country as a whole. The delivery of biodiversity targets in contrast would need to be spatially targeted to promote particular species and habitats where intervention contributes most to national objectives.

In parallel with this, there would be a locally based system of Local Environmental Governance Organisations (LEGO). A LEGO might be seen as the ultimate 'owner' of the local ecosystem, acting as a trustee on behalf of the local community and future generations. Each LEGO would represent local stakeholder interests in identifying natural capital assets within its area and implementing procurement schemes in order to deliver the mix of services that best meets local priorities. This could be based on a natural capital plan to identify a baseline and local priorities, implemented under a constraint to meet sustainability conditions. It might, for instance, adopt a 'strong aggregate capital rule' requiring that the aggregate level of renewable natural capital should be kept at least constant, and profit from the depletion of non-renewable natural capital should be invested in renewable natural capital (Helm, 2015). This might ultimately be set out as a duty on LEGOs as an implementation of a public trust doctrine. Effective decision-making and delivery depends on social and cultural as well as natural capital. Social and cultural capital require investment in relationships and continuity in approach over periods of time rather than policies that change regularly every few years. This should also be nurtured by LEGOs. An outline of the approach is illustrated in Figure 1.

[Figure 1 here]

\section{Public procurement of ecosystem services}

The prevalence of missing markets implies a continuing role for the state in the procurement of ecosystem services on behalf of the general public at multiple levels. Experience with the implementation of agri-environment schemes has identified a variety of approaches that have the 
potential to enhance the cost-effectiveness of procurement schemes (Cullen et al., 2018), such as targeting, competitive tendering and reverse auctions, payment by results or collective contracts.

The procurement approach would seek to expand economic opportunities by creating incentives for delivery to exploit economies of scale and scope. Considerable attention has been given in recent years to catchment planning and landscape scale biodiversity conservation. In order to coordinate land management activities at a sufficient scale it will be necessary to promote cooperation amongst individual land managers. This may be incentivised through paying a premium to land managers who participate in a larger scale plan for ecosystem delivery. Kuhfuss et al., (2016) for instance found that pro-environmental behaviour could be encouraged through a bonus payment made when a pre-defined total area was enrolled. Alternatively, ecosystem delivery could be implemented through farmer associations or cooperatives; the rapid growth of farmer clusters ${ }^{i}$ suggests an enthusiasm for co-operative working. More widely, schemes might be implemented through partnerships comprising collaborations of both land managers and other stakeholders contributing different resources and expertise.

Integration across different ecosystem service delivery takes place at the local scale. Land managers on the ground are best informed as to the opportunities and costs of implementing the delivery of multiple services within a single location. While a national agency might have the capacity to identify the best locations for the delivery of a single service, such as habitat conservation, it cannot know the direct and opportunity costs faced by individual land managers, their expertise and aspirations, or the potential conflicts and synergies amongst different ecosystem services. There are often complementary relationships in the delivery of a range of non-market ecosystem services at a particular location (Austin, et al., 2016). Land management, such as re-wilding, can have the potential to deliver simultaneously biodiversity conservation, landscape enhancement, carbon storage, flood mitigation and public access through a single scheme. The procurement approach should create incentives for land managers to seek out these potential economies of scope.

This suggests that land managers might hold a portfolio with multiple contracts with different agencies for the delivery of different ecosystem services alongside their conventional marketoriented agricultural production. It is clearly important that in this context managers are not paid multiple times for the same work. There are two possible approaches towards this. One would be that effective competition drives bidders to seek only the marginal cost of the extra work required to deliver the extra service being delivered. A second approach might be that larger scale local ecosystem service schemes are negotiated within areas between consortia of service demanders from both public and private sectors, and groups of land holders who can control an area of sufficient scale to be able to deliver multiple services cost-effectively. Such negotiations would be complex and face a challenge of potential free-riding. But they could have the potential to meet multiple demands and, on the basis that they would be expected to continue over relatively long periods of time, would not need to be renegotiated very often.

The system faces considerable uncertainty and a changing environment. The approaches adopted need to adapt as information improves over time. In areas of greatest uncertainty, procurement contracts might be seen as experiments testing alternative approaches towards the desired objectives. For instance, there are numerous ways in which changes in agricultural systems can 
potentially reduce levels of greenhouse gas emissions, but little agreement as to which can be most cost-effective. The accumulation of evidence from monitoring a range of contracts over time would support the development of better guidelines for agricultural practices and provide a clearer focus in conservation efforts.

\section{Securing investments in the longer term}

Relatively short term voluntary instruments, such as have been applied under agri-environment policies, cannot ensure the protection of the environmental gains that are generated in the longer term. At the end of the contract, in the face of changing prices and priorities, either party can withdraw and the land may be returned to intensive and environmentally damaging agricultural uses. Longer term arrangements, such as the transfer of ownership to conservation organisations, the establishment of land trusts or the use of conservation covenants can secure land use changes into the future. Such a long term approach can be especially critical in securing effective ecological restoration or carbon sequestration. This implies that procurement funds should have the flexibility to provide support through a variety of mechanisms, including changes of land ownership and conservation covenants, and not just through the allocation of short term environmental contracts.

There is a tension too between the financial discipline of short term contracts with clear targets, milestones and regular review on the one hand and long term ecological restoration and investment in natural capital on the other. Investments in natural capital may require long term commitment of funding and, especially ex ante, have uncertain outcomes. This challenges the conventional approach to project allocation based on clearly defined outputs to be delivered over a predefined time period. A resolution may be through the development of longer term programme funding where a closer relationship is built up between funder and fundee based on financial transparency and qualitative justification for the actions that are being taken (Hodge and Adams, 2016).

\section{Towards implementation}

Current approaches to agricultural policy are embedded and capitalised into rural systems so that change will not be easy. But we argue that there are substantial potential gains to be had from a change of approach. It is not sufficient simply to set out ambitious targets for long term change. The governance arrangements also need to be put in place in order to determine national and local priorities, to identify and secure the cost-effective land use interventions and to monitor and refine the approaches. While these do not currently exist, there are a number of initiatives often in local areas and relating to individual ecosystem services from which we can learn. At this stage we need better understanding in respect of a range of aspects, such as:

- Mapping and co-ordinating networks of local groups across different ES

- More research and development on governance approaches

- Refining competitive funding mechanisms for procurement at lowest cost

- Developing approaches to longer term programme funding and qualitative assessment

- Understanding potential and limits of PES schemes, risks of crowding out, etc.

This is a long term project. What is required more immediately is a vision of the general approach towards a policy for the delivery of ecosystem services within a devolved framework (Gawith and 
Hodge, 2017). With this goal in view, it will be possible to plot a road map towards the development of the necessary institutions, regulations, funding arrangements and relationships that can make it work. It is necessary to balance the withdrawal of old supports against the introduction of the new approach in order to ensure a smooth transition and minimise the social and environmental harm that might be caused by abrupt change. We should now promote the research, debate and testing needed in order to bring the new approach into practice.

\section{Further Reading}

- Alm, J. and H. S. Banzhaf (2012) Designing Economic Instruments for the Environment in a Decentralized Fiscal System. Journal of Economic Surveys 26(2):177-202.

- Austin, Z., et al. (2016) The co-benefits of biodiversity conservation programmes on wider ecosystem services. Ecosystem Services 20:37-43.

- Batáry, P., Dicks, L. V., Kleijn, D. and Sutherland, W. J. (2015) The role of agri-environment schemes in conservation and environmental management. Conservation Biology 29 (4) 10061016.

- Cullen, P. et al. (2018) Agri-environment scheme design: Past lessons and future suggestions. EuroChoices 17 (3) 26-30.

- Curnow, J. (2018) Delivering a world leading food and farming sector. EuroChoices 17 (2) 1218.

- Dwyer, Janet and Hodge, lan (2016) Governance structures for social-ecological systems: Assessing institutional options against a social residual claimant. Environmental Science and Policy 66, 1-10

- European Commission (2017) CAP Explained: Direct payments for farmers 2015-2020. Agricultural and Rural Development. https://ec.europa.eu/agriculture/sites/agriculture/files/direct-support/directpayments/docs/direct-payments-schemes en.pdf

- Gawith, D. and Hodge, I. (2017) Envisioning a British Ecosystem Services Policy. Policy Brief. University of Cambridge Department of Land Economy and Cambridge Centre for Science and Policy. http://www.csap.cam.ac.uk/links/13/4840/

- Green Alliance (2017) Natural Infrastructure Schemes in practice. Page 38. London.

- Helm, D. (2015) Natural Capital: Valuing the Planet, Yale University Press.

- Hodge, I. (2016) The Governance of the Countryside: Property, Planning and Policy. Cambridge University Press, Cambridge.

- Hodge, I., and W. M. Adams (2016) Short-Term Projects versus Adaptive Governance: Conflicting Demands in the Management of Ecological Restoration. Land 5(4):39.

- HM Government (2018) A Green Future: Our 25 Year Plan to Improve the Environment. https://www.gov.uk/government/publications/25-year-environment-plan

- House of Lords (2017) Brexit: Devolution. European Union Committee. $4^{\text {th }}$ Report of Session 2017-19. HL Paper 9. https://publications.parliament.uk/pa/ld201719/ldselect/ldeucom/9/9.pdf

- IPBES (2019) Global Assessment Report on Biodiversity and Ecosystem Services. Summary for Policymakers. https://www.ipbes.net/news/ipbes-global-assessment-summarypolicymakers-pdf 
- Kuhfuss, L., Préget, R., Thoyer, S., Hanley, N., 2016. Nudging farmers to enrol land into agrienvironmental schemes: the role of a collective bonus. European Review of Agricultural Economics 43, 609-636.

- Lawton, J. H., et al. (2010) Making space for nature: : a review of England's wildlife sites and ecological network. Department for Environment, Food and Rural Development, London.

- Martin, P. (2016)_Ecological restoration of rural landscapes: stewardship, governance, and fairness. Restoration Ecology 24 (5) 680-685.

- OECD (2001) Multifunctionality: Towards and analytical framework. Organisation for Economic Co-operation and Development, Paris.

- OECD (2017) The Governance of Land Use in OECD Countries. Orgainsation for Economic Cooperation and Development, Paris.

- Ostrom, E. (2010). Beyond Markets and States: Polycentric Governance of Complex Economic Systems. American Economic Review 100 (3): 641-72.

- Pe'er, G. et al. (2014) EU agricultural reform fails on biodiversity. Science 344, 1090-1092

- Powney, G., et al. (2019) Widespread losses of pollinating insects in Britain. Nature Communications 10.1018.

- Rockström J. et al. (2017) Sustainable intensification of agriculture for human prosperity and global sustainability. Ambio 46, 4-17.

- RSPB and others. (2016) The State of Nature 2016. The State of Nature partnership.

' Information on the locations of farmer clusters in England and case studies are available at https://www.farmerclusters.com/ (accessed 13 June 2019)

lan Hodge, Department of Land Economy, University of Cambridge, UK Email:idh3@cam.ac.uk

\section{Summary}

Concerns for rural land policy have widened from a focus on food production to include many other critical values, recognised as ecosystems services. But our governance institutions have failed to reflect this. Brexit provides the UK with an opportunity to rethink the governance of rural land. This requires first an assessment of the rights and duties of land ownership. We should explore further the potential for augmented markets and payment for ecosystem services, but the public good character of ecosystem services means that the state will play a major role, through regulation, facilitation, funding and working in partnership with others. The principle of subsidiarity suggests that decisions should be made at different levels: national and local. National policy will procure services for which there is a national commitment or priority, such as for climate change targets or national parks. Local Environmental Governance Organisations will represent local values and priorities articulated through a natural capital plan. Procurement schemes will take account of the experiences gained from agri-environment policies, extended to include partnerships or land purchase. It will take time to build these new institutions. We need more research but what is required now is a clear vision of the potential and a road map of the route towards it.

\section{Pullquote}

"We need to rethink the approach towards the governance of rural land to establish institutions that can deliver outcomes after Brexit" 
Figure 1: A devolved ecosystem services policy approach

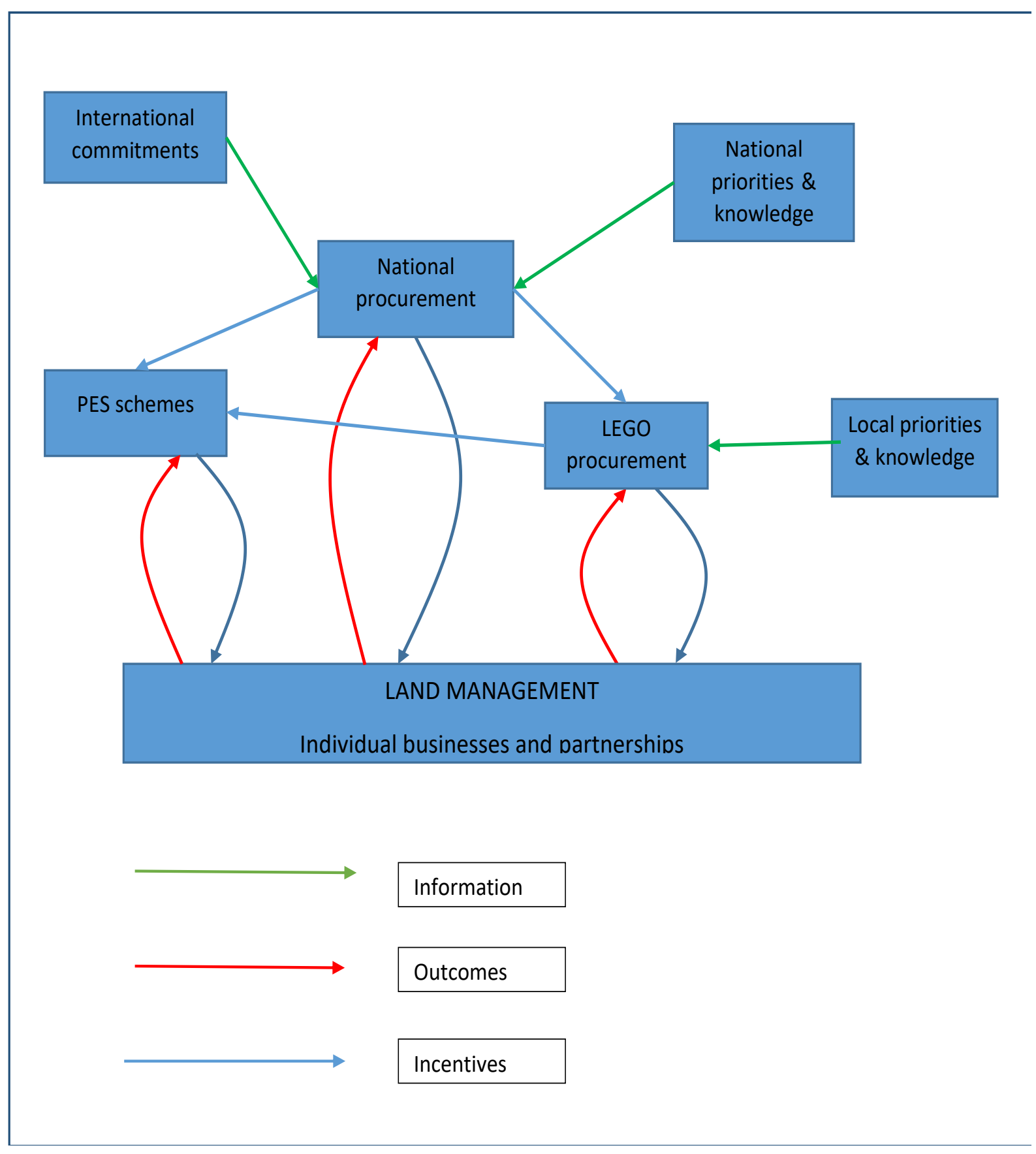

